\title{
The Incidence of Bleeding and the Factors That Influence Its Development among Patients Admitted With Dengue Fever
}

\author{
Thapa KB ${ }^{*}$, Namrata KC², Koirala $\mathrm{T}^{\mathrm{\prime}}$, Bhatttarai $\mathrm{A}^{2}$ \\ 'Consultant Physician \& Lecturer, Department of Medicine, ${ }^{2}$ Lecturer, Department of Pediatrics, \\ Gandaki Medical College \& Teaching Hospital, Pokhara, Nepal
}

\section{Keywords \\ Bleeding, Dengue fever, \\ Thrombcytopenia. \\ Corresponding author \\ *Krishna Bahadur Thapa \\ Consultant Physician \& Lecturer \\ Department of Medicine \\ Gandaki Medical College \& Teaching \\ Hospital, Pokhara, Nepal \\ Email: krish_thapa09@yahoo.com}

\begin{abstract}
Background: Dengue virus is now classified as a major global health threat by the World Health Organization. Bleeding is a common complication and is one of the most feared. There is an increase incidence in the adult population, hence, the focus of this study.

Objectives: To determine the incidence of bleeding and the factors that influence its development among patients admitted with dengue fever at Fatima Medical Center, Phillipines from January 2009 to December 2011.

Methods: This is a case control study using chart review. The incidence of bleeding is calculated using risk ratio. Factors affecting bleeding are determined using chi square for qualitative variables and T-test or ANOVA for quantitative variables. Simultaneous determination of factors association with bleeding will be analyzed using multiple logistic regression. Level of significance will be set at alpha $=0.05$.

Results: The female sex is significantly more prone to develop bleeding $(\mathrm{p}=0.044)$. There is no significant increase in bleeding in patients who have co-morbidities $(\mathrm{p}=0.447)$. In every one unit increase in WBC ( $1 \mathrm{x}$ 109 ) the odds of bleeding decrease by $15 \%$. For every one unit increase in hematocrit the odds of bleeding decreases by $6.8 \%$. For every one unit increase in platelet count the odds of bleeding decreases by $3 \%$ that is every 10 unit increase in platelet count the odds of bleeding decrease by $22.9 \%$.
\end{abstract}

Conclusions: Female sex, a low initial WBC and platelet count will increase a patient's propensity to develop bleeding.

\section{INTRODUCTION}

Dengue fever is the most common arboviral illness. It is now classified as a major global health threat by the World Health Organization (WHO) and estimates that presently about two-fifths of the world population is at risk of this viral infection ${ }^{1}$. Dengue was first reported in 1780 , when Benjamin Rush described this condition as "break-bone fever". It is a mosquito-borne viral infection caused by four serotypes ${ }^{2}$. Infection with dengue virus causes a broad spectrum of illnesses, ranging from asymptomatic infection, undifferentiated fever and classical dengue fever (DF) to the more severe forms dengue hemorrhagic fever (DHF) and dengue shock syndrome (DSS) with high rates of morbidity and mortality ${ }^{3,4}$. Infection with one serotype of dengue virus (DENV) provides lifelong immunity to that serotype, but results only in partial and transient protection against subsequent infection by the other three serotypes. It is well documented that sequential infection with different DENV serotypes increases the risk of developing dengue hemorrhagic fever (DHF). There is currently no specific treatment for DENV infection, although several potential vaccines are 
in development; therefore, the only method of preventing DENV transmission is vector control ${ }^{5,6}$.

The pathognomonic feature of DHF is an increase in systemic vascular permeability resulting in reduced intravascular plasma volume, with progression to hypovolemic shock in severe cases ${ }^{8}$. Thrombocytopenia and coagulopathy are also prominent features of symptomatic infection. Severe thrombocytopenia and increased vascular permeability are two major characteristics of dengue hemorrhagic fever (DHF). An immune mechanism of thrombocytopenia due to increased platelet destruction appears to be operative in patients with $\mathrm{DHF}^{7,8}$. This study will focus on adult patients with bleeding and thrombocytopenia. Bleeding is a common complication of dengue and is one of the most feared. Bleeding is caused by capillary fragility and thrombocytopenia and may manifest in various forms, ranging from petechial skin hemorrhages to life-threatening gastrointestinal bleeding ${ }^{9.10}$.

Most Dengue related literature is focused in the pediatric population, as dengue fever used to be mainly a pediatric problem ${ }^{11,12}$. Recent trends show an increasing incidence of dengue fever in the adult population, hence the focus of this study. The internist when faced with a patient with dengue fever should also take into consideration the presence of co-morbid conditions such as diabetes and hypertension ${ }^{13}$. The increasing incidence of dengue fever and dengue hemorrhagic fever and the fact that it is no longer seasonal but occurs all year round makes it necessary to conduct studies regarding its complications, since morbidity in the adult population will also have an economic impact ${ }^{14}$.

Furthermore, one of the aims is to decrease the mortality resulting from dengue fever. As bleeding is a common complication of dengue fever, this study aims to determine some factors that will influence its development.

\section{METHODS}

This is a case control study conducted in patients admitted at Fatima Medical Center during the study period. Sample size was calculated with the following assumptions; assuming that in the general population based on previous studies $27 \%$ will develop bleeding and $42 \%$ among those with co-morbid conditions. With an alpha error of 0.05 powers of $90 \%$ one tailed alternative hypothesis sample size will be equal to 170 per group $\mathrm{x} 2$ for two groups. Adding $25 \%$ for each variable controlled, a total of 680 sample sizes will be collected for four (4) additional control variables. Chart review of all patients admitted due to dengue fever during the study period, January 2009 - December 2011.

Charts of all patients admitted with dengue fever and developed bleeding during the course in the ward are reviewed. CBC results are tabulated. The results are analyzed with the use of the appropriate statistical tool.

\section{Selection of Subjects}

\section{Inclusion Criteria}

Patients admitted at Fatima Medical Center diagnosed with dengue fever according to WHO criteria.

\section{Exclusion Criteria}

Patients with bleeding but with other causes other than dengue fever.

Patients with blood dyscrasias

\section{Variable Description and Definition of Terms}

\section{Dependent variable}

Bleeding: Bleeding is defined as spontaneous bleeding, more than two $\mathrm{ml}$ in quantity seen by a doctor. The bleeding is visible in any part of the body. The bleeding includes vaginal bleeding and upper GI bleeding manifested as melena.

\section{Independent variable}

\section{Co-morbid conditions:}

Hypertension: Two office reading of a BP more than $130 / 80$, and or having maintenance anti-hypertensive medications.

Diabetes: Diabetes is defined based on the ADA criteria of a FBS more than $126 \mathrm{mg} / \mathrm{dL}$ and two hours PPBS of more than $200 \mathrm{mg} / \mathrm{dL}$ and or having maintenance medications for diabetes.

\section{Sex:}

Male

\section{Female}

\section{Previous Dengue:}

With previous dengue: Doctor diagnosed dengue fever in the past.

Without previous dengue.

Hematologic Parameters: All laboratory parameters must be done in Fatima Medical Center for standardization.

Platelet Count: Normal Count (150 - 450 x 10 9/L)

WBC: $(5.0-10 \times 10.9 / \mathrm{L})$

\section{Hematocrit Level:}

Male: $0.42-0.49$

Female: $0.37-0.42$

\section{Statistical Tool}

The incidence of bleeding is calculated using risk ratio. The factors affecting bleeding are determined using Chi square for qualitative variables and T-test or ANOVA for 
quantitative variables initially using univariate analysis. Simultaneous determination of factors association with bleeding will be analyzed using multiple logistic regression. Level of significance is set at alpha $=0.05$.

Determination of the relationship between dengue fever and factors that are qualitative in nature were analyzed initially using chi-square test in the univariate analysis. Factors that are quantitative in nature were analyzed by using logistic regression. All factors related to dengue fever were then analyzed in the multivariate analysis using multiple logistic regression.

\section{RESULTS}

The profiles of 702 patients who had dengue fever, based on the WHO criteria were analyzed. Out of the 702 patients who fulfilled the WHO criteria of dengue fever 132 developed bleeding during the course of confinement. The demographic characteristics, past medical history, course in the wards and hematologic parameters of the subjects were then analyzed.

Table 1 shows the demographic characteristics of the patients included in this study. The total number of subjects 702, 385 (55\%) were males and 318 (45\%) were females.

Table 1: Demographic Characteristics



Based on the figures above, majority of the subjects were single $(82.9 \%)$. However $27.9 \%$ of the married subjects developed bleeding compared to only $17 \%$ of the singles population.
Table 2: Previous dengue infection

\begin{tabular}{|c|c|c|c|c|c|c|}
\hline & \multicolumn{5}{|c|}{ Bleeding } & \multirow[b]{3}{*}{$P$ value } \\
\hline & & \multicolumn{2}{|c|}{ Yes } & \multicolumn{2}{|r|}{ No } & \\
\hline & & $\begin{array}{c}\text { Num- } \\
\text { ber }\end{array}$ & $\begin{array}{c}\text { Per- } \\
\text { centage }\end{array}$ & $\begin{array}{c}\text { Num- } \\
\text { ber }\end{array}$ & $\begin{array}{c}\text { Per- } \\
\text { centage }\end{array}$ & \\
\hline \multirow{3}{*}{$\begin{array}{l}\text { Previous } \\
\text { Dengue }\end{array}$} & No & 119 & $18.6 \%$ & 521 & $81.4 \%$ & \multirow{3}{*}{0.648} \\
\hline & Yes & 13 & $21.0 \%$ & 49 & $79.0 \%$ & \\
\hline & Total & 132 & $18.8 \%$ & 570 & $81.2 \%$ & \\
\hline
\end{tabular}

Sixty two subjects have previous dengue fever. Twenty one percent ( $21 \%$ ) of those subjects developed bleeding during the course of confinement.

Table 3: History of blood transfusion

\begin{tabular}{|c|c|c|c|c|c|}
\hline & \multicolumn{3}{|c|}{ Bleeding } \\
\hline & & & Yes & No & Total \\
\hline \multirow{7}{*}{$\begin{array}{l}\text { Previous } \\
\text { blood } \\
\text { transfu- } \\
\text { sion }\end{array}$} & \multirow{4}{*}{ Yes } & Count & 9 & 3 & 12 \\
\hline & & $\%$ within & $75.0 \%$ & $25.0 \%$ & $100.0 \%$ \\
\hline & & Previous Blood & & & \\
\hline & & Transfusion & & & \\
\hline & \multirow[t]{3}{*}{ No } & Count & 123 & 567 & 690 \\
\hline & & $\%$ within & $17.8 \%$ & $82.2 \%$ & $100.0 \%$ \\
\hline & & $\begin{array}{l}\text { Previous Blood } \\
\text { Transfusion }\end{array}$ & & & \\
\hline \multirow[t]{4}{*}{ Total } & & Count & 132 & 570 & 702 \\
\hline & & $\%$ within & $18.8 \%$ & $81.2 \%$ & $100.0 \%$ \\
\hline & & Previous Blood & & & \\
\hline & & Transfusion & & & \\
\hline
\end{tabular}

Table 3 shows the subjects who have a previous history of blood transfusion. Among the subjects 12 have a history of previous blood transfusion. Among the 12, nine (75\%) developed bleeding during the course in the ward and three (25\%) did not. Among the 690 subjects who have no previous history of blood transfusion, 123 developed bleeding and 567 did not.

Table 4: Course in the ward, including blood transfusion, presence of bleeding and blood products transfused

\begin{tabular}{llcc}
\hline & & Number & Percentage \\
\hline BT hospital & Yes & 42 & $31.8 \%$ \\
& No & 90 & $68.2 \%$ \\
Blood & Total & 132 & $100.0 \%$ \\
products & Platelet concentrate & 33 & $68.8 \%$ \\
transfused & Fresh frozen plasma & 14 & $29.2 \%$ \\
& Total & 1 & $2.1 \%$ \\
Site of & Gums/Lips & 48 & $100.0 \%$ \\
bleeding & Nose & 31 & $29.0 \%$ \\
& Urinary tract & 29 & $27.1 \%$ \\
& Vaginal & 19 & $17.8 \%$ \\
& GI & 23 & $21.5 \%$ \\
& Vaginal/Nose & 2 & $1.9 \%$ \\
& Nose/Gums & 2 & $1.9 \%$ \\
& Lungs & 1 & $.9 \%$ \\
& Total & 0 & $.0 \%$ \\
\hline
\end{tabular}


Table 4 shows the course of the patient in the ward. Among the subjects, $31.8 \%$ had blood transfusion during the course of their hospital stay. Platelet concentrate is the most common blood product that was transfused (68.8\%) followed by fresh frozen plasma and PRBC. The most common site of bleeding is the oral mucosa, the gums and the lips with $29 \%$; this is followed by the nose at $27.1 \%$ and vaginal bleeding in the form of menstruation (21.5\%). Other bleeding sites are the urinary tract, manifested as hematuria and GI tract.

Table 5: Sex, previous dengue and co-morbid conditions in relation to bleeding

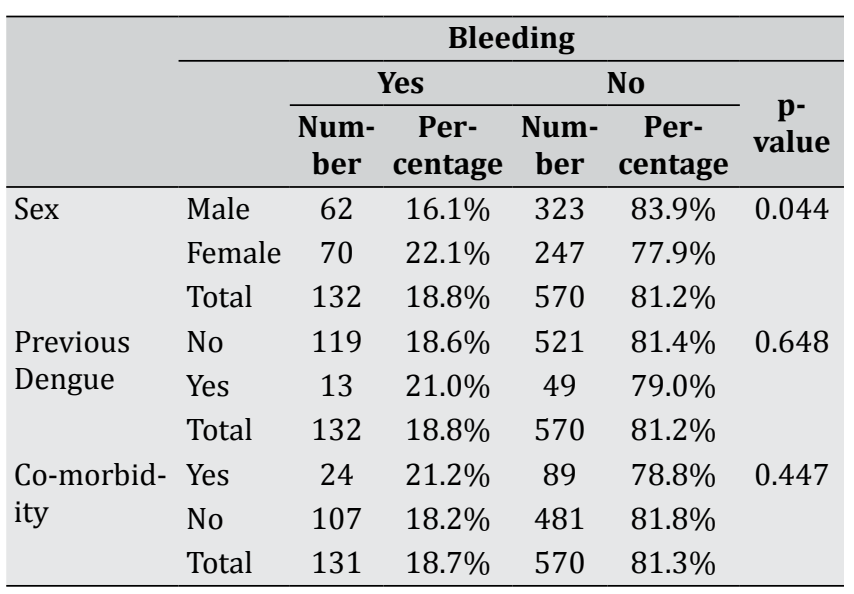

Table 5 shows these factors that influence a dengue patient to develop bleeding. Among the factors studied are sex, previous dengue and co-morbid conditions (diabetes and hypertension).

Table 6: Hematologic parameters

\begin{tabular}{|c|c|c|c|c|c|}
\hline & \multirow{2}{*}{ B } & \multirow{2}{*}{$\begin{array}{c}\text { p- } \\
\text { value }\end{array}$} & \multirow{2}{*}{$\begin{array}{c}\text { Odds } \\
\text { Ratio } \\
\text { (OR) }\end{array}$} & \multicolumn{2}{|c|}{ 90\% C.I.for OR } \\
\hline & & & & Lower & Upper \\
\hline Lowest WBC & -0.161 & 0.003 & 0.851 & 0.779 & 0.930 \\
\hline $\begin{array}{l}\text { Lowest Hema- } \\
\text { tocrit }\end{array}$ & -0.065 & 0.001 & 0.937 & 0.908 & 0.967 \\
\hline $\begin{array}{l}\text { Lowest Platelet } \\
\text { Count }\end{array}$ & -0.026 & 0.000 & 0.974 & 0.968 & 0.981 \\
\hline Initial WBC & -0.128 & 0.036 & 0.880 & 0.796 & 0.973 \\
\hline $\begin{array}{l}\text { Initial Hema- } \\
\text { tocrit }\end{array}$ & -3.192 & 0.148 & 0.041 & 0.001 & 1.542 \\
\hline $\begin{array}{l}\text { Initial Platelet } \\
\text { Count }\end{array}$ & 0.004 & 0.134 & 1.004 & 1.000 & 1.008 \\
\hline
\end{tabular}

Table 6 shows that in every one unit increase in WBC $\left(1 \times 10^{9}\right)$ the odds of bleeding decreases by $15 \%$. For every one unit increase in hematocrit the odds of bleeding decreases by $6.8 \%$. For every one unit increase in platelet count the odds of bleeding decreases by $3 \%$ that is every 10 unit increase in platelet count the odds of bleeding decreases by $22.9 \%$. For every one unit increase in the initial WBC the odds of bleeding decreases by $12 \%$.
Table 7: Multivariate analysis of hematologic parameters, sex and serologic studies

\begin{tabular}{|c|c|c|c|c|c|}
\hline & \multirow{2}{*}{ B } & \multirow{2}{*}{$\begin{array}{c}p \text { - } \\
\text { value }\end{array}$} & \multirow{2}{*}{$\begin{array}{c}\text { Odds } \\
\text { Ratio } \\
\text { (OR) }\end{array}$} & \multicolumn{2}{|c|}{ 90\% C.I.for OR } \\
\hline & & & & Lower & Upper \\
\hline Lowest WBC & -0.247 & .000 & .781 & .711 & .858 \\
\hline $\begin{array}{l}\text { Lowest Hemato- } \\
\text { crit }\end{array}$ & -0.067 & .001 & .935 & .904 & .967 \\
\hline $\begin{array}{l}\text { Lowest Platelet } \\
\text { Count }\end{array}$ & -0.024 & .000 & .976 & .970 & .982 \\
\hline $\begin{array}{l}\text { Sex (Male: } \\
\text { Female) }\end{array}$ & -0.603 & .006 & .547 & .382 & .784 \\
\hline $\begin{array}{l}\text { Number of Days } \\
\text { Febrile During } \\
\text { Admission }\end{array}$ & -0.199 & .013 & .820 & .718 & .935 \\
\hline $\begin{array}{l}\text { Dengue Ns1Ag } \\
\text { ( Positive: } \\
\text { Negative) }\end{array}$ & .570 & .104 & 1.769 & .993 & 3.152 \\
\hline $\begin{array}{l}\text { IgG ( Positive: } \\
\text { Negative) }\end{array}$ & 1.080 & .000 & 2.945 & 2.030 & 4.271 \\
\hline $\begin{array}{l}\text { Co- morbidity } \\
\text { (Present: Absent) }\end{array}$ & .505 & .080 & 1.657 & 1.030 & 2.666 \\
\hline
\end{tabular}

Table 7 shows that in every one unit increase in WBC, the odds of bleeding decreases by $22 \%$ holding all others variable constant. For every one unit increase in platelet count the odds of bleeding decreases by $21.3 \%$. The odds of bleeding ratio among female and male is $2: 1$. Every one day increase in number of days fever, the odds bleeding of decreases by $18 \%$.The odds of bleeding among those with NS1Ag positive is 1.76 times greater than of bleeding to those who has negative NSAg.

\section{DISCUSSION}

As seen in the Table 1 majority of the subjects were students, with age ranging from 20 - 30 years and came from the Valenzuela area. According to an epidemiological study in Belgium, Dengue Fever is typically acknowledged to be a childhood disease and is an important cause of pediatric hospitalization in Southeast Asia. There is, however, evidence of increasing incidence of DHF among older age groups. Since the early 1980s, several studies in both Latin America and Southeast Asia have reported a higher association of DHF with older ages. In some Southeast Asian countries where dengue has been epidemic for several years, this age shift is clearly observed, indicating an epidemiological change in dengue infection in those locations ${ }^{14}$. This study is focused on the adult population and did not include pediatric cases. The trend for increased incidence among young adults has important implications for control and prevention. Sixty two subjects had previous dengue fever. Twenty one percent (21\%) of those subjects developed bleeding during the course of confinement to develop complications. Previous studies states that a past history of dengue fever is a contributory factor to a more 
complicated second dengue infection. A study on adult patients in Sri Lanka states that there were instances where the primary infection resulted in severe complications, such as shock syndrome ${ }^{9}$. The figures in Table 2 shows a $p$ value of 0.648 which means that having a previous episode of dengue fever may be a factor for the chances of bleeding.

The premise is to evaluate if factors such as sex, previous dengue and co-morbid conditions, will increase a patient's chance to develop bleeding during the course of confinement. There is no significant increase in bleeding in patients who have co-morbidities $(\mathrm{p}=0.447)$. A previous study done on adult patients with dengue fever and DHF showed that age above 65 years, history of dengue infection, diabetes mellitus, hypertension and renal insufficiency have been identified as being significantly associated with DHF/DSS ${ }^{10}$. The aforementioned study mentioned that the presence of co-morbidities will increase the risk to develop DHF, but not necessarily bleeding. Compared to the results obtained in this study, which shows that the presence or absence of a co-morbid condition has no impact on the risk of a patient to develop bleeding. In this study patients with co-morbid conditions that increases bleeding risks, such as liver and blood pathologies, was not included.

A Case Control Study on the risk factors for DHF, states that, although it is unclear why some cases of dengue fever progress to DHF/DSS, there is weak evidence that some diseases could have a role in this process, such as diabetes, hypertension, and allergies. It further showed that individuals who reported having allergies, or those who reported diabetes, were two and a half times as likely to have DHF. The explanation of the authors why diabetes mellitus patients have an increased risk in developing bleeding or Dengue Shock Syndrome is that Type II diabetes, reduces the use of glucose by the organism, changes the anatomical and physiological integrity of the endothelium due to a permanent inflammatory condition caused by activation of T-lymphocytes.

There is no significant relationship between bleeding and co-morbid conditions ( $\mathrm{p}=0.447)$. Another paper on Dengue Shock Syndrome and co-morbid conditions states that although no statistically significant association was found between hypertension and DHF, it is interesting that when individuals without hypertension were taken as a reference group, a clear trend was found for an increased likelihood of DHF among those who reported having hypertension but did not use any antihypertensive medication followed by hypertensive individuals who used more than one antihypertensive drug ${ }^{13}$.

Literature review has shown that the history of a previous dengue infection will increase the patients risk to develop a severe form of dengue, however, it was not mentioned that a previous dengue infection will increase the risk of bleeding. In this study previous dengue infection does not correlate with increased risk of bleeding ( $\mathrm{p}=0.648)$.

Sex is also a risk factor in the development of a more severe infection. In this study, the $p$ value is significant, showing that the female sex is more prone to develop bleeding. Comparing the results of this study to previous researches shows that three independent studies from epidemics in India and Singapore found nearly twice the number of male patients compared to females, with a male to female ratios of $1.9: 1$ in Singapore and $1: 0.57$ in New Delhi. Another study found a male to female ratio of $1: 0.25$ cases for DSS. However, of the three deaths in this study, two were females ${ }^{15}$. The reason for this discrepancy is that this study considered vaginal bleeding and menstruation, which was not included in the other studies. In the previous studies although males have an increased bleeding risk, it also showed that females have a higher incidence to develop a more complicated course.

The data in this research has similar results with two studies done in Asia which shows that severe illness and case fatality rate were consistently higher among females despite higher incidence in males. As early as 1970, a paper on Dengue Fever stated that males predominate among those with milder disease but females account for more severe illness and suggested that either immune response in females is more competent than in males, resulting in greater production of cytokines, or the capillary bed of females is prone to increased permeability ${ }^{14}$.

The result of this study is useful for doctors to predict if a patient will develop bleeding and to take measures to prevent mortality in bleeding patients. The data gathered is useful for the physician in counseling of the patient, as bleeding is a feared complication of the disease. There are already various researches done on bleeding and thrombocytopenia, but most are done in children so this study will be able to provide a data for the adult population.

\section{CONCLUSIONS}

Female sex, a low initial WBC and platelet count will increase a patient's propensity to develop bleeding. The presence of a positive Dengue Ns1Ag will also increase the risk of bleeding. Serial monitoring of $\mathrm{CBC}$ is imperative in the management of dengue fever, since changes in hematologic values is a factor in the development of bleeding. Previous dengue infection is a factor in the development of a more severe second dengue infection, but it does not increase a patient's risk to develop bleeding. The presence of a co-morbid condition, namely hypertension and diabetes has no effect on the risk of a patient to develop bleeding. 


\section{REFERENCES}

1. World Health Organization. Dengue guidelines for diagnosis, treatment, prevention and control. New edition. Geneva: World Health Organization; 2009.

2. Guzman MG, Halstead SB, Artsob H, Buchy P, Farrar J, Gubler DJ et al. Dengue: A continuing global threat. Nat Rev Microbiol. 2010; 8 (12 Suppl): S7-16.

3. Lee IK, Liu JW, Yang KD. Clinical and laboratory characteristics and risk factors for fatality in elderly patients with dengue hemorrhagic fever. The American Journal of Tropical Medicine and Hygiene. 2008; 79(2): 149-153.

4. Wichmann 0 et al. Risk factor and clinical features associated with severe dengue infection in adults and children during the 2001 epidemic in Chonburi Thailand. Trop Med Int Health. 2004; 9(9): 1022-9.

5. Narayanan M, Aravind MA, Thilothammal N, Prema R, Sargunam CS, Ramamurty N. Dengue fever epidemic in Chennai - A study of clinical profile and outcome. Indian Pediatr. 2002; 39(11): 1027-33.

6. Malavige GN, Fernando S, Fernando DJ, Seneviratne SL. Dengue viral infections. Postgrad Med J. 2004; 80(948): 588-601.

7. Krishna Murti C, Kalayanarooj S, Cutting MA, Peat RA, Rothwell SW, Reid TJ, Green S, Nisalak A, Endy TP, Vaughn DW, Nimmannitya S, Innis BL. Mechanisms of Hemorrhage in Dengue without Circulatory Collapse.
Am. J. Trop. Med. Hyg. 65(6); 2001; 840-847.

8. Wills B, Tran VN, Nguyen TH et al. Hemostatic changes in Vietnamese children with mild dengue correlate with the severity of vascular leakage rather than bleeding. The American Society of Tropical Medicine and Hygiene. 2009; 81: 4.

9. Kularatnae SAM, Gawarammana IB, Kumarasiri PRV. Epidemiology, clinical features, laboratory investigations and early diagnosis of dengue fever in adults: A descriptive study in Sri Lanka. South East Asian J Trop Med Public Health. May 2005; 36: 3.

10. Teo D. Ng LC, Lam S. Is Dengue a threat to the blood supply? Transfus Med. 2009 Apr; 19(2): 66-77.

11. Narayanan M, Aravind MA, Thilothammal N, Prema R, Sargunam CS, Ramamurty N. Dengue fever epidemic in Chennai - A study of clinical profile and outcome. Indian Pediatr. 2002; 39(11): 1027-33.

12. Malavige GN, Fernando S, Fernando DJ, Seneviratne SL. Dengue viral infections. Postgrad Med J. 2004; 80(948): 588-601.

13. Maria Apalcida Figurado et al. Allergies and diabetes as risk factors for dengue hemorrhagic fever: Results of a case control study. PLoS Negl Trop Dis. 2010 Jun; 4(6): e699.

14. Debarati-Guha Sapir. Dengue Fever: New paradigms for a changing epidemiology. Emerging themes in epidemiology. $2005 ; 2: 1$ 